\title{
Die FMH auf der Anklagebank
}

Wir publizieren in dieser Ausgabe die Klage und Kläger der FMS gegen die Einführung TARMED. Diese Klage veranlasst zu folgenden Feststellungen:

1. Der ZV hält an der Einführung der TARMEDTarife im KVG-Bereich auf 1. Januar 2004 fest; er sieht aktuell auch keine Veranlassung, den UV-/MV-/IV-Vertrag zu kündigen.

2. Der ZV wird das Ziel einer stetigen Verbesserung der TARMED-Tarifstruktur weiterverfolgen, auch wenn RE II nicht zum gewünschten Ziel geführt hat.

3. Der ZV hält insbesondere auch an der Schaffung eines auf TARMED basierenden Belegarzttarifs fest; nur so können die - vom ZV immer anerkannten - Probleme der Belegärzte gelöst werden ... eine Position des ZV und der FMH seit 1993.

4. Die Kläger und ihr Umfeld pochen auf den im Demokratieverständnis unseres Landes tief verankerten Minoritätenschutz. Richtig ist, dass die Interessen auch kleinster Minoritäten während jahrelanger Verhandlungen analysiert und in die TARMED-Tarifstruktur eingebracht wurden. Es kann aber nicht an- gehen, dass eine Minorität eine in der Urabstimmung 2002 klare Majorität weiter majorisieren will. Wer solches tut, setzt sich dem Vorwurf des Missbrauchs demokratischer Institutionen aus.

5. Es ist hier nicht der Ort, sich über Inhalt und Berechtigung der Klage der FMS auszulassen; der ZV äussert sich - schon aus prozessualen Gründen - prinzipiell nie zu hängigen Rechtsverfahren. Die Kollateralschäden dieser Klage aber können klar abgeschätzt werden: Es ist - neben Zehntausenden von Franken Prozesskosten aus Mitgliederbeiträgen - die Tatsache, dass eine kleine Minorität aus in Wahrheit mehr als durchsichtigen Motiven die gesamte Ärzteschaft einmal mehr zu Geisseln der Medien macht. Dies ist nachgerade unerträglich geworden.

Wie auch immer: Wir werden zusammen mit der Schweizerischen Eidgenossenschaft nun auf der Anklagebank sitzen, eine Ehre, die einem ja auch nicht alle Tage widerfährt.

Dr. med. H. H. Brunner, Präsident FMH 